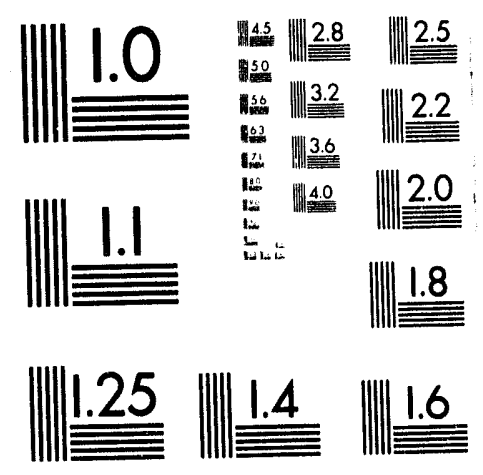



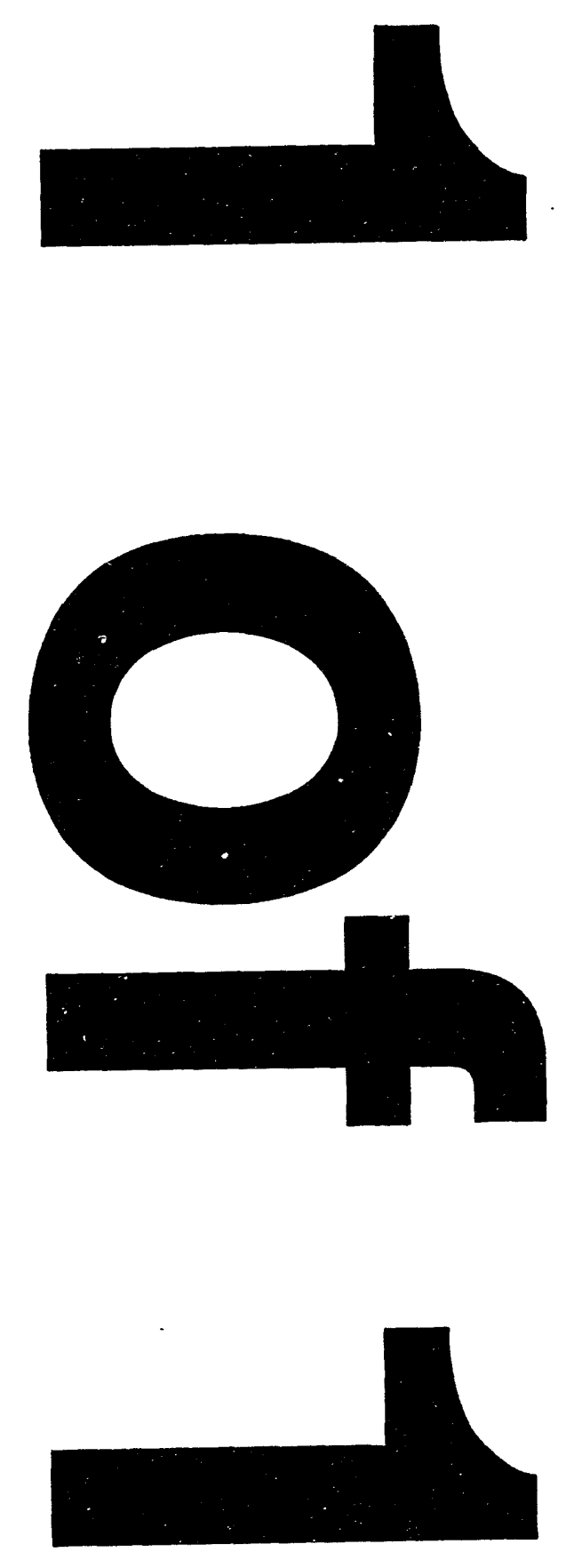


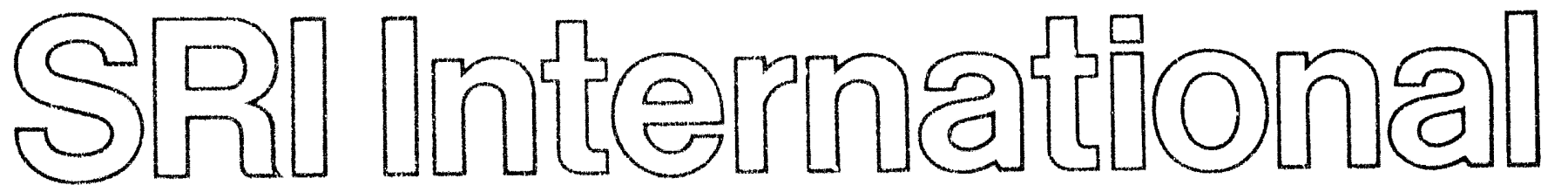

RECLVED

MAR 281994

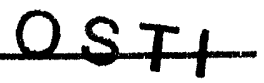

SRI Report No. 2847-27, - Quarterly Report No. 9

ITJanuary 1994

\section{FUNDAMENTAL STUDIES OF COAL LIQUEFACTION}

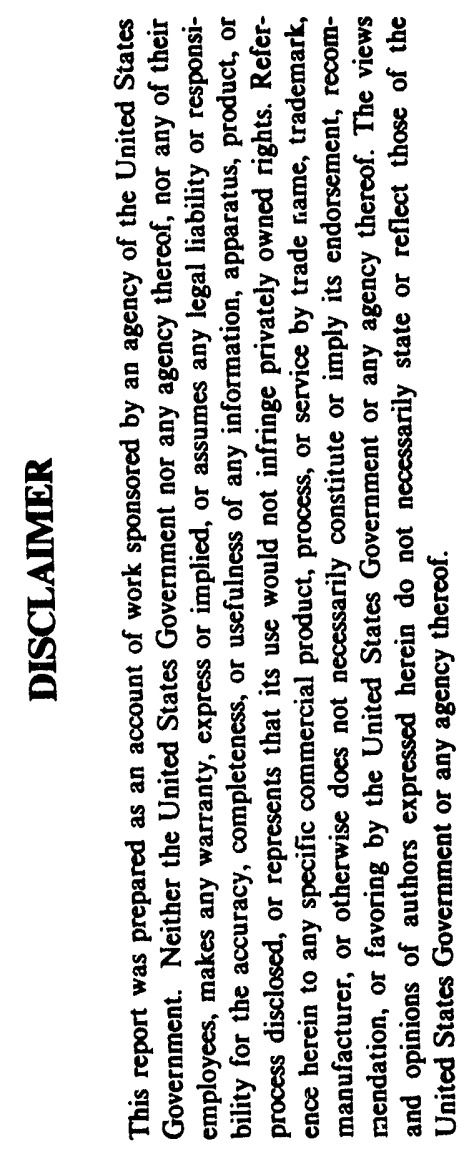

David S. Ross

Chemistry Laboratory

Covering the Period October 1, 1993 to January 1, 1994

Prepared for:

U. S. Department of Energy

Pittsburgh Energy Technology Center

P. O. Box 10940, MS 921-165

Pittsburgh, PA 15236

Contract No. DE-AC22-91PC91053

Approved:

David M. Golden

Vice President

Physical Sciences Division 


\section{INTRODUCTION AND BACKGROUND}

In our last report we discussed the effects of water, $n$-undecane, and argon as media ir the pyrolysis of Illinois No. 6 coal. We noted that the apparent swelling of the coal in a few atm of argon and its shrinking in water at $200 \mathrm{~atm}$ both began at about $300^{\circ} \mathrm{C}$, suggesting that the events shared some common chemistry. The swelling appeared to be the seeping of a tar from the coal particles, the cores of which remained unchanged during the process. A fraction of the particles appeared to melt abruptly and entirely to a fluid phase, much like a crystalline organic compound. The process concluded with the rapid evaporation of the tar, leaving behind the remains of the initial particles with sizes and shapes very similar to the starting particles.

We noted next that in contrast, the areas of the particles resulting from pyrolysis in water were smaller than then initial particles. This result suggested that water prompted conversion of the coal beyond what dry pyrolysis provided.

We also discussed our findings in $n$-undecane at $200 \mathrm{~atm}$ where the particles remained fully unchanged in size and shape to temperatures above $450^{\circ} \mathrm{C}$. Other data from earlier work suggested moreover that the alkane medium acted to suppress the evolution of thermally generated tar from the coal, and that with extended heating the tar was ultimately and irreversibly incorporated into the bulk coal matrix. The fact water did not act in this way and instead elicited conversion supports the view that it is an active participant in the conversion, and prompts the question of what might be added to the water to promote that process even further.

\section{CURRENT RESULTS}

The results obtained over the past period include studies in our cell with Wyodak coal, and argon, water, $n$-undecane, and tetralin as media. The argon work was conducted at $7 \mathrm{~atm}$ and the others at $200 \mathrm{~atm}$, and the results are shown in Figure 1. In the undecane study one particle was monitored, while for the other media the figure shows the results for 3 particles in each case. Smooth curves have been sketched in for clarity, and it is apparent that there is good agreement within each set overall.

As we saw with Illinois No. 6 coal, in argon the particles began to swell at around $300^{\circ} \mathrm{C}$, and develop a fluid-like appearance. As just noted, the phenomenon appears to be the development of a tar, which is slowly expelled from the particles with increasing temperature. The overall thermal behavior was essentially the same for the three particles, but the extent of the tar 
development was different within them, apparently reflecting different levels of tar precursors in the individual particles.

Again as or Illinois No. 6, there was an abrupt evaporation of the tar at around $350^{\circ} \mathrm{C}$. The residue was a collection of particles very similar in size and shape to the starting particles.

The behavior in water was also like that seen for the Illinois coal. The coal began to shrink at around $300^{\circ} \mathrm{C}$, or at the same point at which the tar evolution began in argon. The shrinking continued to around $350^{\circ} \mathrm{C}$, at which point there was a curious, momentary swelling. This action continued only briefly and the particles then resumed shrinking up to the highest temperature attained. [It can be noted here that in all of our more recent experiments with water there has been a smooth transition through the critical temperature $\left(\mathrm{T}_{\mathrm{c}}\right)$ at $374^{\circ} \mathrm{C}$. In our runs conducted over the past 6 months we have not experienced the optical difficulties we noted in earlier accounts near $T_{c}$. We have no explanation for the improvement, except to suggest that the earlier work was often complicated by an improper seating of the gold gaskets which sealed the diamond windows against the steel cell body. It is thus not unlikely that our earlier optical problems were tied to leakage and local pressure fluctuations, which, with experience, have been overcome ]

The undecane result was also like that seen for the Illinois coal. Thus in marked contrast to the argon and water results, there was no change in size nor shape of the coal particles.

Finally, Figure 1 also shows data with tetralin as medium, and the results display yet another type of behavior. In this case, much like the results for undecane, there is no change in the particles to about $425^{\circ} \mathrm{C}$. At that point they begin to shrink very rapidly, consistent with the temperature range at which coal conversion becomes active in tetralin (Gorin, 1981).

\section{DISCUSSION}

\section{The Role of Water and the Action of Organic Media}

A family of observations with several media has been developed over the course of this program, with surprisingly little difference apparent in the results for Ilinois No. 6 and Wyodak coals. A summary of the findings is sketched in Figure 2, which is assembled in terms of the following rationale.

The primary event in the heating of coal is the evolution of tars, starting at around $300^{\circ} \mathrm{C}$, which emerge from the pores in the coal. That process, clearly seen in our experiments with argon 


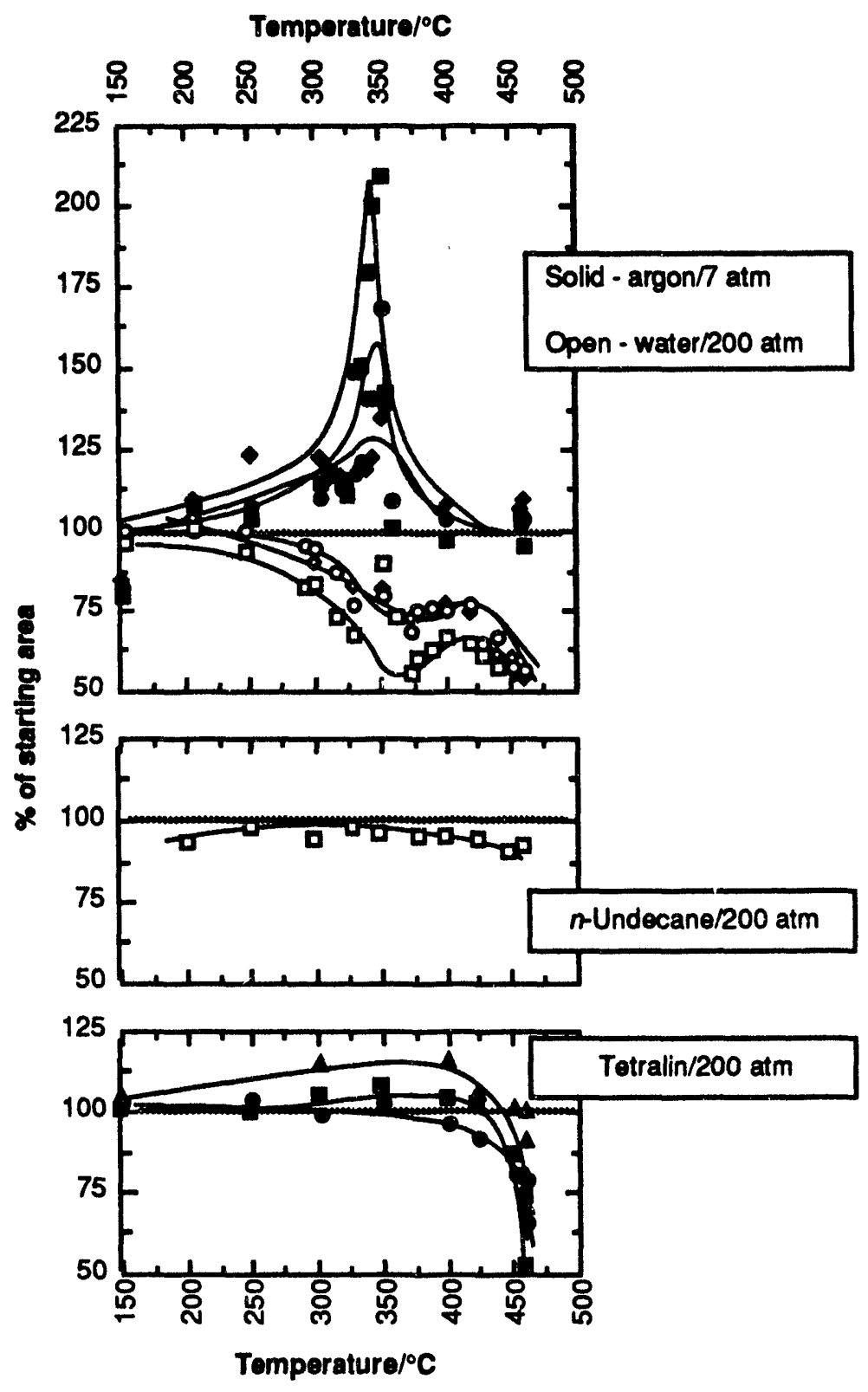

Figure 1. Changes brought about in the pyrolysis of Wyodak coal in argon, water, tetralin, and n-undecane.

as medium, is followed by an abrupt evaporation of the tars at $350-375^{\circ} \mathrm{C}$.

Our results with water can then be satisfactorily explained, recognizing that liquid water under hydrothermal conditions is both a highly diffusive medium and a very good solvent for organic compounds. (Naphthalene and liquid water are miscible in all proportions at $300^{\circ} \mathrm{C}$, for 
example; see accounts cited in Ross, 1984; and Ross, et al., 1991a). Thus at around $300^{\circ} \mathrm{C}$ 'Nater will thoroughly penetrate the coal, and the evolved tars, so readily apparent with argon as the medium, dissolve in the aqueous phase are not visible. And since in the aqueous case there is a net reduction in particle size, water must be a reactant as well, possibly hydrolyzing key ether links within the structure.

This scenario is consistent with the findings in our earlier FIMS work with Wyodak coal under hydrothermal conditions (Ross, et al., 1991b). In that study, conducted in quartz-lined reactors at conditions of $350^{\circ} \mathrm{C}$ for $30 \mathrm{~min}$ or $5 \mathrm{hr}$, we found tars deposited on the quartz liners at the end of a run corresponding to $7-8 \%$ of the starting coal, but solely in the case of added water as medium. No tar was found when the coal was heated in control runs with the water replaced by $\mathrm{N}_{2}$ (a few atm) or undecane. Thus we submit that the tars, soluble in the water, were transported to the liner walls and deposited when the reactor was cooled.

The case for organic media must be very different. In the present work we have seen that for both undecane and tetralin media there is no change in the particles well beyond the $300^{\circ} \mathrm{C}$ point where tars develop. As discussed above, our earlier work showed that a hydrocarbon medium suppresses tars evolution, and in the case of a nonreactive hydrocarbon such as undecane they become irreversibly incorporated in the coal matrix. We can surmise that lipophobic interactions between the hydrocarbon medium and the coal could tend to close or clog the pores through which the tars pass. Thus as the figure shows, for undecane the result is a char.

In the case of the tetralin, however, that process is joined by another at $\sim 425^{\circ} \mathrm{C}$. At that temperature some reductive chemistry begins, reflected as an abrupt shrinking of the coal. The reduction is commonly explained as being triggered by the homolytic scission of thermally weak bonds in the coal. Our data, however, are not consistent with such a scheme, as is discussed in the following section.

\section{The Existence of Key, Labile Links in Coal}

The identification of key, thermally weak links in coal, and indeed whether such links exist at all, are questions central to the understanding of coal behavior, and are still unanswered. Several models to explain the thermal behavior of coal, such as that proposed recently by Solomon, et al. (1991, 1993 a, b), describe the formation of light gases and tars in an initial, thermally promoted depolymerization. That step is then followed by condensation of aromatic clusters to resolidify the material. A keystone of the model is the presumed existence of links such as $\mathrm{Ar}-\mathrm{CH}_{2}-\mathrm{CH}_{2}-\mathrm{Ar}$ and $\mathrm{Ar}-\mathrm{CH}_{2}-\mathrm{O}-\mathrm{Ar}$ joining large portions of the structure. They are positioned 
as key bridges, readily breaking homolytically to free radical fragments at $350-450^{\circ} \mathrm{C}$, which are then rapidly capped by $\mathrm{H}$-donor regions of the coal.

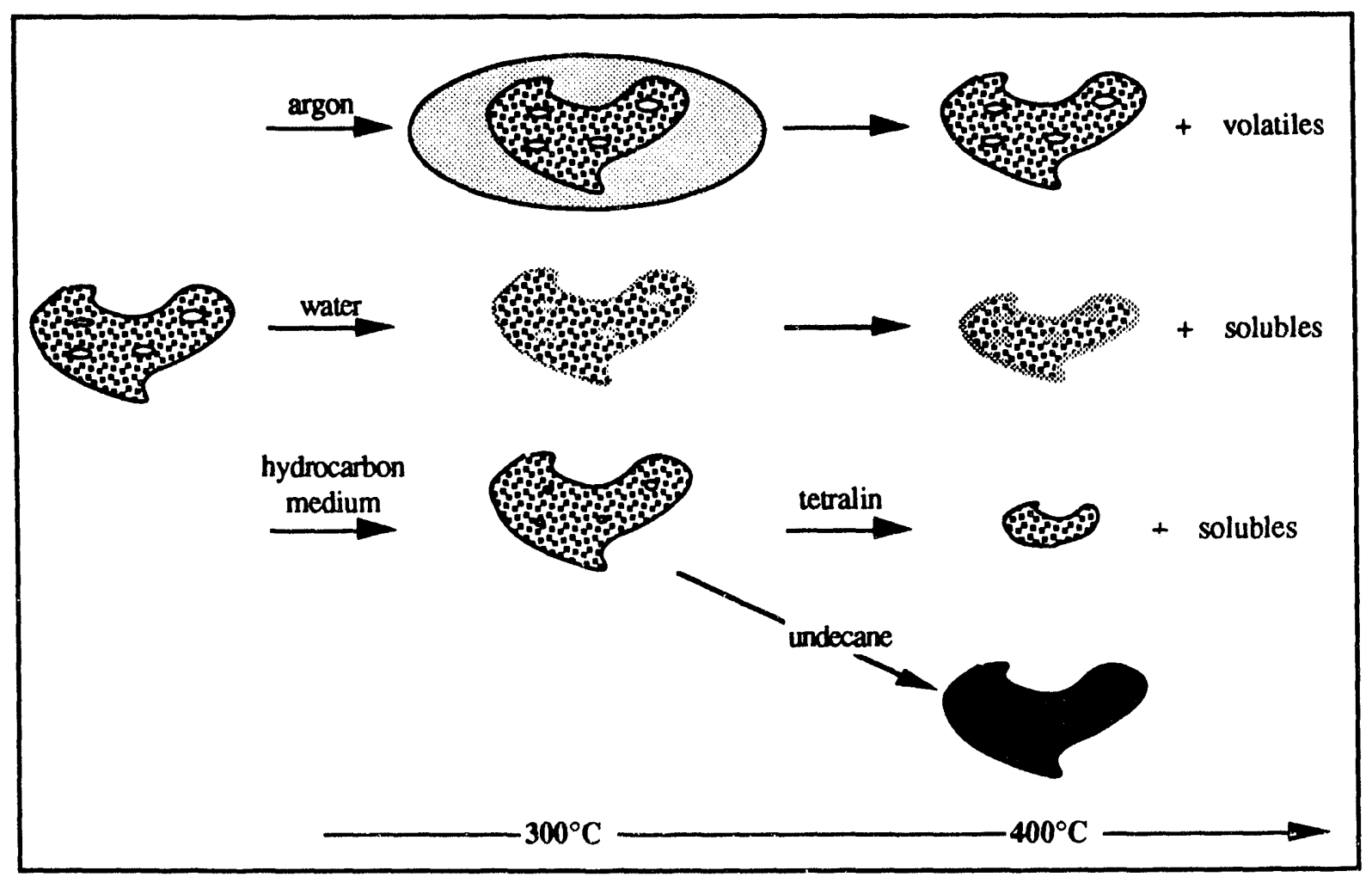

Figure 2. Summary of our data from the heating of coal in four media.

The same links are of course commonly used to explain the liquefaction of coal in H-donor media such as tetralin. In that case the thermally generated radical fragments are capped by the donor medium.

To our knowledge, however, there is no direct experimental evidence demonstrating their presence. Solomon and coworkers present some indirect support $(1991,1993 \mathrm{~b})$, including Arrhenius plots developed from tar release and weight loss providing $\mathrm{E}_{\mathrm{a}}$ values in the 190-230 $\mathrm{kJ} / \mathrm{mol}$ (45-55 kcal/mol) range expected for labile bridge cleavage. Other support includes proton magnetic resonance thermal analysis which shows increased proton mobility of bulk coal up to about $430^{\circ} \mathrm{C}$, reversing to return to starting values above that point, and Giesler plastometer work 
showing increased fluidity to around that same temperature, and then a rapid decline at higher temperatures.

It must be noted, however, that the $\mathrm{E}_{\mathrm{a}}$ values are based on assigned preexponential factors. There is thus still an arbitrary element to the argument; there are apparently no firm, unambiguous kinetic data to employ in the delineation of this important point. And while the nmr and plastometer findings unquestionably demonstrate increased bulk fluidity, they plainly do not compellingly demonstrate labile bridge breaking. Thus the actuality of thermally weak, key links in coal is still unconfirmed.

Some of our data may have some direct bearing on this point. Both pyrolysis and liquefaction are dependent on the kinetics of the same homolytic step, which should be rate controlling for both cases, and it then follows that both tar formation and liquefaction should be initiated at the same temperature. Our findings, however, show that for both Wyodak and Illinois No. 6 coals, liquefaction begins at temperatures at least $100^{\circ}$ higher than tar production. Clearly, different initiating processes are operating in the two events.

This topic will be discussed in detail in our Final Report, which is now in preparation.

\section{REFERENCES}

Gorin, E., 1981. "Fundamentals of Coal Liquefaction," in Chemistry of Coal Utilization, Second jupplementary Volume, M. Elliott, Ed., Wiley-Interscience, New York, 1845-1918.

Ross, D. S., 1984. "Coal Conversion in Carbon Monoxide Water Systems" in Coal Science, J. Larsen, I. Wender, and M. Gorbaty, eds., 3 301-338.

Ross, D. S. and Loo, B., 1991a. "Hydrothermal Pretreatment of Coal," Final Report for SRI Project 8209, DOE Contract No. DE-AC22-89PC89880, Pittsburgh Energy Technology Center, U.S. Department of Energy.

Ross, D., Loo, B., Tse, D., and Hirshcon, A., 1991b. "Hydrothermal Treatment and the Oxygen Functionalities in Wyodak Coal", Fuel, 70, 289-295.

Solomon, P., Hamblen, D., Serio, M., Yu, Z., and Charpenay, S., 1991. "Can Coal Science be Predictive" (Storch Award Presentation), Prepr. Pap.-Am. Chem. Soc., Div. Fuel Chem., 36(1), 267-300.

Solomon, P., Fletcher, T., and Pugmire, R., 1993a. "Progress in Coal Pyrolysis," Fuel, 22 (5), 587-597.

Solomon, P., Hamblen, D., Serio, M., Yu, Z., and Charpenay, S., 1993b. "A Characterization Method and Model for Predicting Coal Conversion Behavior," Fuel, 72, 469-488. 

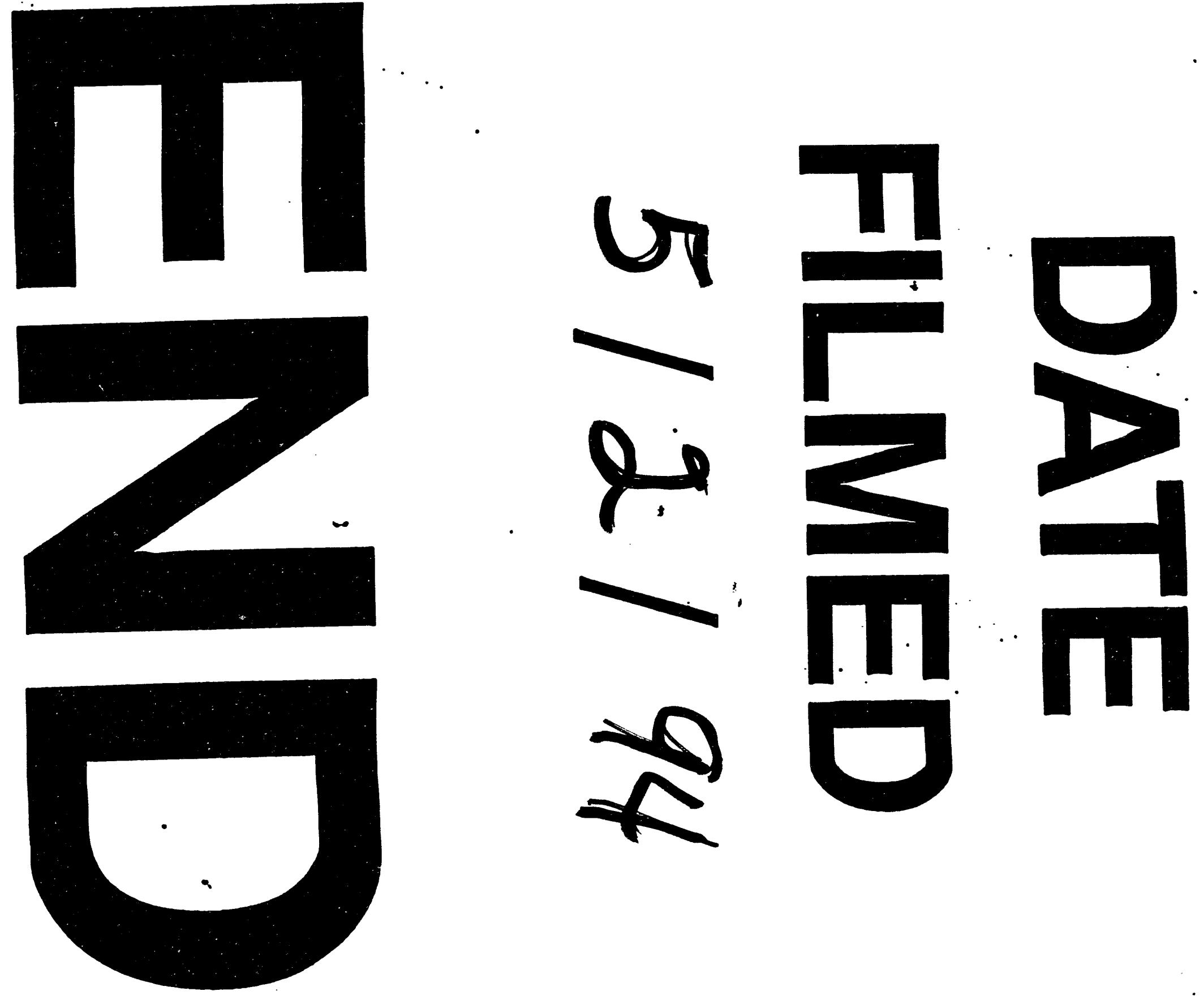
